\title{
The Microbiome of Oral Squamous Cell Carcinomas: a Functional Perspective
}

\author{
Nezar N. Al-Hebshi ${ }^{1} \cdot$ Wenche S. Borgnakke ${ }^{2} \cdot$ Newell W. Johnson $^{3,4,5}$
}

Published online: 18 April 2019

(C) The Author(s) 2019

\begin{abstract}
Purpose of Review This decade has witnessed increasing interest in the potential role of the oral microbiome in head and neck cancers, particularly oral squamous cell carcinoma (OSCC). Most studies have focused on the bacterial component of the microbiome (bacteriome), but the fungal component (mycobiome) is also receiving attention. In this review, we provide an overview of mechanisms by which the microbiome can contribute to oral carcinogenesis, and summarize results from clinical studies, especially focusing on those reporting functional microbiome analysis. Synthesizing and illustrating the evidence, we also suggest a new "passenger-turning-driver" functional model for the role of the microbiome in oral cancer.

Recent Findings In vitro studies provide convincing evidence for the carcinogenicity of the periodontal bacteria Fusobacterium nucleatum and Porphyromonas gingivalis. However, results from clinical studies are inconsistent, with significant variations in composition of the microbiome associated with oral cancer. Methodological differences may partially explain the differing conclusion. However, variations observed may also reflect functional redundancy: the phenomenon that different species may be enriched in different samples, but still serve the same functions. Indeed, functional analyses of the bacteriome associated with oral cancer have revealed more consistent results, namely enrichment of a virulent, inflammatory bacteriome in the tumors.

Summary Apart from oncoviruses associated with a special entity of oral cancer, no consistent evidence implicates specific microbial species in OSCC etiology. Instead, the disturbed function of an initially "passenger" microbiome within the tumor microenvironment likely contributes to tumor progression by sustaining chronic inflammation.
\end{abstract}

Keywords Carcinoma $\cdot$ High-throughput nucleotide sequencing $\cdot$ Mouth neoplasms $\cdot$ Microbiota $\cdot$ Mycobiome $\cdot$ Squamous cell

\section{Introduction}

Oral cancer (predominantly squamous cell carcinoma) is a subset of head and neck cancers (HNCs) affecting the oral cavity proper, i.e., mouth anterior to the palatine tonsils, also referred to as intraoral. In the international databases, oral cancer is classified as "lip

This article is part of the Topical Collection on Microbiology

Nezar N. Al-Hebshi

alhebshi@temple.edu

1 Oral Microbiome Research Laboratory, Maurice H. Kornberg School of Dentistry, Temple University, 3223 North Broad Street, Room \# L213, Philadelphia, PA 19140, USA

2 Department of Periodontics and Oral Medicine, University of Michigan School of Dentistry, 1011 North University Avenue, Room\# G049, Ann Arbor, MI 48109-1078, USA and oral cavity": ICD-10 sites C00-C06. These constitute the 16th most prevalent malignancy worldwide, accounting for an estimated 247,563 new cases and 177,384 deaths annually [1]. There is, however, marked geographical and cultural variation. In much of South Asia, for example, oral cancer is the most common cancer among males, perhaps sixth among women, and

3 Menzies Health Institute Queensland, Griffith University, Building G40, Room 9, Brisbane, Queensland 4222, Australia

4 School of Dentistry and Oral Health, Griffith University, Brisbane, Queensland, Australia

5 Faculty of Dentistry, Oral and Craniofacial Sciences, King's College London, London, UK 
second overall [2]. In the USA, the corresponding numbers are 35,130 and 7410 , respectively, although the anatomical sub-sites do not precisely match those used in the worldwide data [3]. There is a male predilection and the tongue is the most commonly affected sub-site [3]. In the West, nearly $74 \%$ of oral squamous cell carcinoma (OSCC) cases are attributed to tobacco smoking and heavy alcohol consumption [4], while in South Asia and the Pacific, smokeless tobacco and areca (betel) nut chewing are the major risk factors [5]. Unlike cancers of the oropharynx, only a small fraction of OSCC cases $(2-6 \%)$ are attributed to human papilloma virus (HPV) infection [6,7] —although greater proportions are reported from the Asia-Pacific Region - but there are questions about definitions of head and neck sub-sites and laboratory methods [8]. Around $15 \%$ of all OSCC cases remain unexplained by any of the known risk factors. In addition, and despite advances in cancer treatment modalities, OSCC continues to have poor prognosis with 5-year survival rates less than $50 \%$ in much of the world $[9,10]$. These challenges have triggered scientists to search for novel risk factors and prognosis modifiers that eventually could present targets for preventive or therapeutic interventions. Particularly, there has been increasing interest in the role of the oral microbiome in oral carcinogenesis [11].

Apart from the debate on its origin [12], the term "microbiome" is currently used to refer to "all microorganisms in a particular habitat and their collective genomes" [13]. The microbiomes associated with the human body, including the oral microbiome, and their role in health and disease have been studied extensively [14]. Due to differences in key ecological factors, such as redox potential, attachment legends, moisture level, acidity, etc., there are significant variations in the composition of the microbiome from one body site to another, and even between sub-sites in close proximity, e.g., sub- and supra-gingival plaque [15]. The human microbiomes form complex, but balanced (homeostatic), communities that are compatible with health, a status increasingly referred to as normobiosis. Under certain circumstances, however, this balance may be disturbed, leading to perturbations in the composition and function of the microbiome (dysbiosis) that are associated with transition from health to disease [16]. In the oral cavity, dental caries and periodontitis are typical examples of diseases associated with microbial dysbiosis. Bacteria are the predominant microorganisms in the oral cavity and therefore most research so far has focused on the bacterial component of the oral microbiome - the oral bacteriome. However, there is increasing interest in less abundant microbial communities, such as those involving fungi, the oral mycobiome $[17,18]$, and viruses, the oral virome [19], respectively, and their potential role in oral diseases. The advent of high-throughput molecular technologies, especially next-generation sequencing (NGS), has revolutionized the study of microbial communities. An overview of nucleic acid sequencing-based methods currently used to study the oral microbiome is provided in Fig. 1.
Evidence is emerging for the oral microbiome playing a role in oral cancer, a topic we reviewed comprehensively in 2016 [11]. Nonetheless, there has been a virtual explosion in research in this area (at least 18 additional studies since that report), with evolving concepts regarding the nature of contributions by the oral microbiome to oral carcinogenesis, which consequently warrants revisiting the topic. In this concise review, we summarize results from clinical studies on the bacteriome and mycobiome associated with oral cancer, and provide an overview of carcinogenic properties of some oral microbes. We also propose a new functional model for the role of the microbiome in oral carcinogenesis.

\section{Carcinogenicity of Specific Oral Microbes}

\section{The Classical Microbial Suspects: Viruses}

The vast majority of microbes designated as Class 1 carcinogens by the International Agency for Research on Cancer (IARC) are viruses. Therefore, viruses come to mind first when raising a question regarding the role of microorganisms in cancer. As far as HNCs are concerned, two families of oncogenic viruses are particularly important: Human Papillomaviruses (HPVs) and Human Herpesviruses (HHVs). There is currently incontrovertible evidence that a small number of so-called highrisk (hr) HPVs are responsible for a global epidemic of oropharyngeal cancer. By now, cancer of the oropharynx has replaced cancer of the uterine cervix as the most common HPV-related cancers in the USA [20]. A smaller proportion of intra-oral cancers are also caused by hrHPVs. Although these HPVs are epitheliotropic, cancerous lesions mostly arise in the mucosa associated with lymphoid tissue, due to interactions between lymphocytes and keratinocytes, namely in the posterior third of the tongue (such lesions located in the palatine tonsils and elsewhere in Waldeyer's tonsillar ring are not classified as intraoral). The underlying cellular mechanisms are well understood: HPV E6 and HPV E7 oncogenes interfere with p53 and retinoblastoma gene proteins, respectively, and thereby block their tumor suppressor actions [21]. Consequently, there are encouraging possibilities to block the oncogenic pathways with interfering ribonucleic acid (RNA) or by gene editing [22].

Among the HHVs, the Epstein-Barr virus (HHV-4) is the major cause of nasopharyngeal cancers, a distinct biological entity [23]. However, there is limited evidence that HHV-4 may play a role in oral cancer [21, 24]. HHV-8 is the etiologic agent for Kaposi's sarcoma located in the mouth and elsewhere that is prevalent in immunosuppressed individuals, particularly in patients with acquired immune deficiency syndrome (AIDS) [21, 25]. The virus is carried in the oropharynx and can be recovered from saliva/oral fluid samples $[21,26]$. There is circumstantial evidence that Herpes Simplex Viruses (HSV), both HSV-1 and HSV-2, are associated with oral (and 


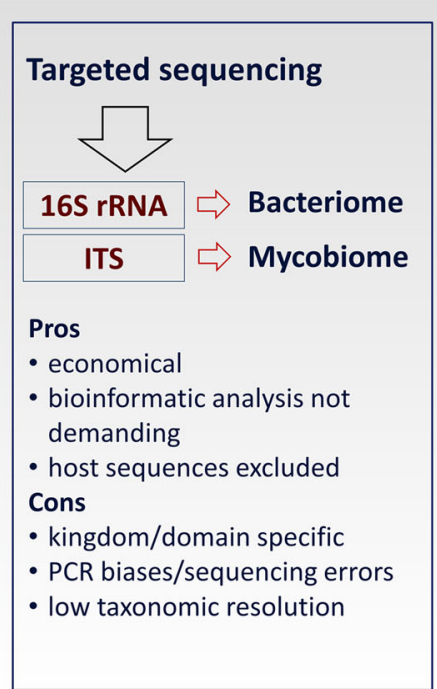

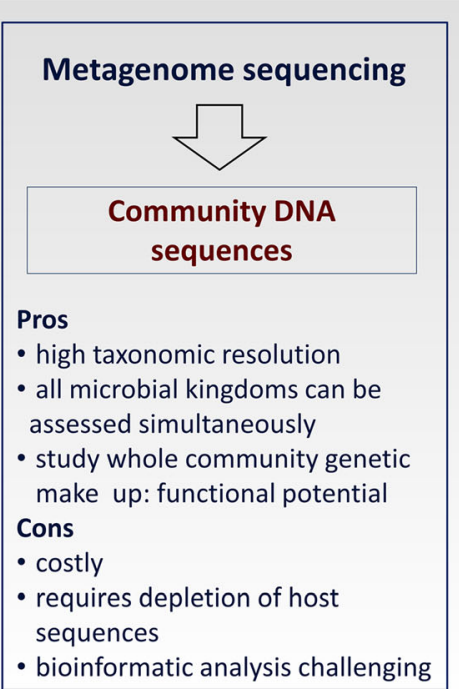

Fig. 1 Nucleic acid sequencing-based methods currently used to study the oral microbiome. In targeted sequencing, domain-specific primers are used to amplify a marker gene; the generated amplicons (libraries) are then sequenced. Typically, taxonomic profiles at the genus level are obtained. In metagenome sequencing, DNA from the entire microbial community (after depleting host DNA) is fragmented and sequenced. Proper analysis can provide strain-level profiles as well as the functional potential of the microbiomes. In metatranscriptome analysis, microbial mRNA (after depleting ribosomal RNA as well as host mRNA) is used to contract cDNA libraries that are then sequenced. Many sequencing platforms are available on the market. cons disadvantages (from "pro et contra" Latin "for and against"), DNA deoxyribonucleic acid, ITS internal transcribed spacer, $m R N A$ messenger RNA, $P C R$ polymerase chain reaction, pros advantages, $r R N A$ ribosomal ribonucleic acid cervical) squamous cell carcinoma in humans, as well as supportive animal studies [21], but a direct oncogenic role remains unsubstantiated [26].

Apart from human viruses, the oral cavity is also home to a complex community of bacteriophages that are thought to influence the ecology and pathogenicity of the oral bacterial community [27]. Whether or not this phage community plays a role in oral carcinogenesis has not been explored.

\section{Emerging Role of Porphyromonas gingivalis and Fusobacterium nucleatum}

In the 1990s, the relationship between bacteria and carcinogenesis was first established by demonstrating the causative role of Helicobacter pylori in gastric cancer [28], and since then, tremendous efforts have been invested in exploring the relationship between bacteria and cancer in sites elsewhere in the body. This has led to uncovering additional associations, such as that of Chlamydia trachomatis with cervical cancer [29], Salmonella typhi with gallbladder cancer [30], and Bacteroides fragilis with colon cancer [31]. As far as oral cancer is concerned, evidence is emerging, primarily from in vitro and animal studies, for the carcinogenicity of the periodontal bacteria Porphyromonas gingivalis ( $P$. gingivalis) and Fusobacterium nucleatum ( $F$. nucleatum). Interest in these two bacteria from the oral microbiome as potential carcinogens has been fueled by studies that implicated them in pancreatic and colorectal cancers (CRC), respectively [32-35].
The mechanisms by which they are thought to contribute to oral carcinogenesis are shown conceptually in Fig. 2 [11].

$P$. gingivalis has been shown to inhibit apoptosis at different levels, including activation of JAK1/STAT3 and PI3K/Akt signaling pathways [36, 37], suppression of proapoptotic BCL-2-associated death promoter [38], blocking activity of caspase-3 and caspase-9 [37, 38], upregulation of microRNA-203 [39], and prevention of ATP-dependent P2 $\mathrm{X}_{7}$-mediated apoptosis [40]. Both $P$. gingivalis and $F$. nucleatum activate cell proliferation through upregulation of kinases and cyclins [41-43], activation of the $\beta$-catenin signaling pathway $[44,45]$, and downregulating level of the p53 tumor suppressor [41]. They also have been found to enhance cellular invasion, primarily through upregulation/ activation of matrix metalloproteinases, including MMP-1, MMP-9, MMP-10, and MMP-13, and inducing stemness and epithelial to mesenchymal transition (EMT) [43, 46-48]. In addition, $P$. gingivalis and $F$. nucleatum are believed to contribute to progression of oral cancer by inducing chronic inflammation via increasing production of pro-inflammatory cytokines [49-52]. Production of carcinogenic substances, such as acetaldehyde (from ethanol), may also play an important role, but has not been documented for these two species. Nonetheless, there is evidence for such production by other oral microorganism species, such as Streptococci [53], Neisseria [54], and Candida [55, 56].

Despite the convincing evidence from in vitro studies on the carcinogenicity of $P$. gingivalis and $F$. nucleatum just 
1

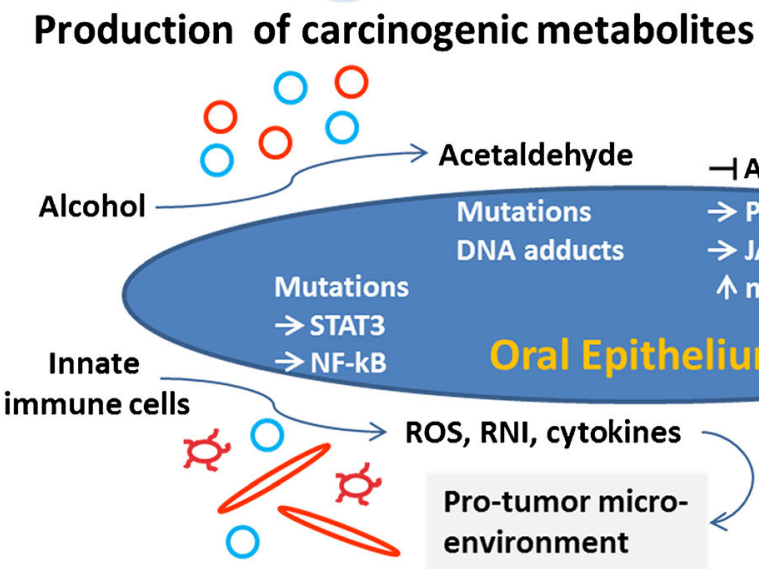

Induction of chronic inflammation
2

Inhibition of apoptosis

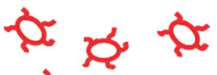

-े

$\rightarrow$ PIBK /AKt

$\rightarrow$ JAK1/STAT3

$-1 p 53$

$\rightarrow \beta$-catenin

miR-203

$\rightarrow$ NF-kB $\uparrow$ Cyclins

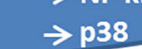

$\rightarrow$ p38

MMPs

EMT

Stemness

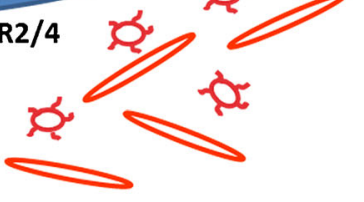

\section{Activation of cell} proliferation
Fig. 2 Mechanisms by which specific oral bacteria may induce/ contribute to oral cancer. The figure was reproduced with permission [11]. More details are described in the text. ROS reactive oxygen

summarized, evidence for a direct carcinogenic role in oral cancer based on clinical studies is still lacking, as described in the following section.

\section{The Bacteriome Associated with Oral Cancer: Clinical Studies}

\section{Variations in Composition of the Bacteriome Associated with Tumors}

Clinical studies that assessed the association between bacteria and cancers of the oral cavity are summarized in Table 1. Most of these studies restricted inclusion to OSCC samples, but a number of them also included HNCs located at sites other than the oral cavity (parts of the pharynx, larynx, or esophagus) as well as lesions that were only potentially malignant. Only two decades ago, namely in 1998, Nagy and collaborators first demonstrated differences in composition of the microbial community colonizing the surface of OSCC and adjacent normal tissue, using culture techniques [57•]. Between 2000 and 2005, Streptococcus anginosus (S. anginosus) became implicated in the etiology of HNC, including OSCC, by research groups from Japan [58, 59, 61]. However, these studies suffered from lack of proper control samples: the high detection rates of the bacterium observed in HNC samples were simply because it is a normal colonizer of the oropharynx. Interest in S. anginosus thus faded quickly. species, $R N I$ reactive nitrogen intermediates, MMPs matrix metalloproteinases, $P A R$ protease-associated receptor, $E M T$ epithelial to mesenchymal transition

In 2006, Hooper et al. demonstrated, for the first time, the presence of a viable complex bacterial community within the OSCC tissues that is compositionally different from that found in the tumors' healthy margins [62•]. Since then, the vast majority of investigations have employed sequencing of the $16 \mathrm{~S}$ rRNA (ribosomal RNA) gene to characterize the microbiomes in study samples, initially with the Sanger method and more recently with NGS chemistries [63, 65-70, 71•, $72-79,80 \bullet, 81,82,83 \bullet, 84]$. Nevertheless, there are significant methodological differences between these studies in terms of (1) the type of samples analyzed (saliva (stimulated or unstimulated), surface swabs, or biopsies); (2) the nature of control or comparison samples used (tumor-adjacent, clinically normal; contralateral to tumor; healthy subject; or benign lesions); (3) the hypervariable region of the 16S rRNA gene selected for sequencing (e.g., V1-V3 or V4-V5); and (4) the bioinformatic analysis method used for analysis of sequencing data (sequence quality control, reference database, and taxonomy assignment algorithm). The latter particularly affects taxonomic resolution, with only a few studies reporting specieslevel profiles and the rest limited to the genus level.

As displayed in Table 1, a number of bacterial taxa, particularly Fusobacterium spp., and to a lesser extent, Campylobacter, Parvimonas, and Prevotella spp., were repeatedly found to be significantly enriched in OSCC samples (Table 1), whereas Streptococci frequently were found in association with health. Nevertheless, a more careful examination of the results from these studies reveals there are 


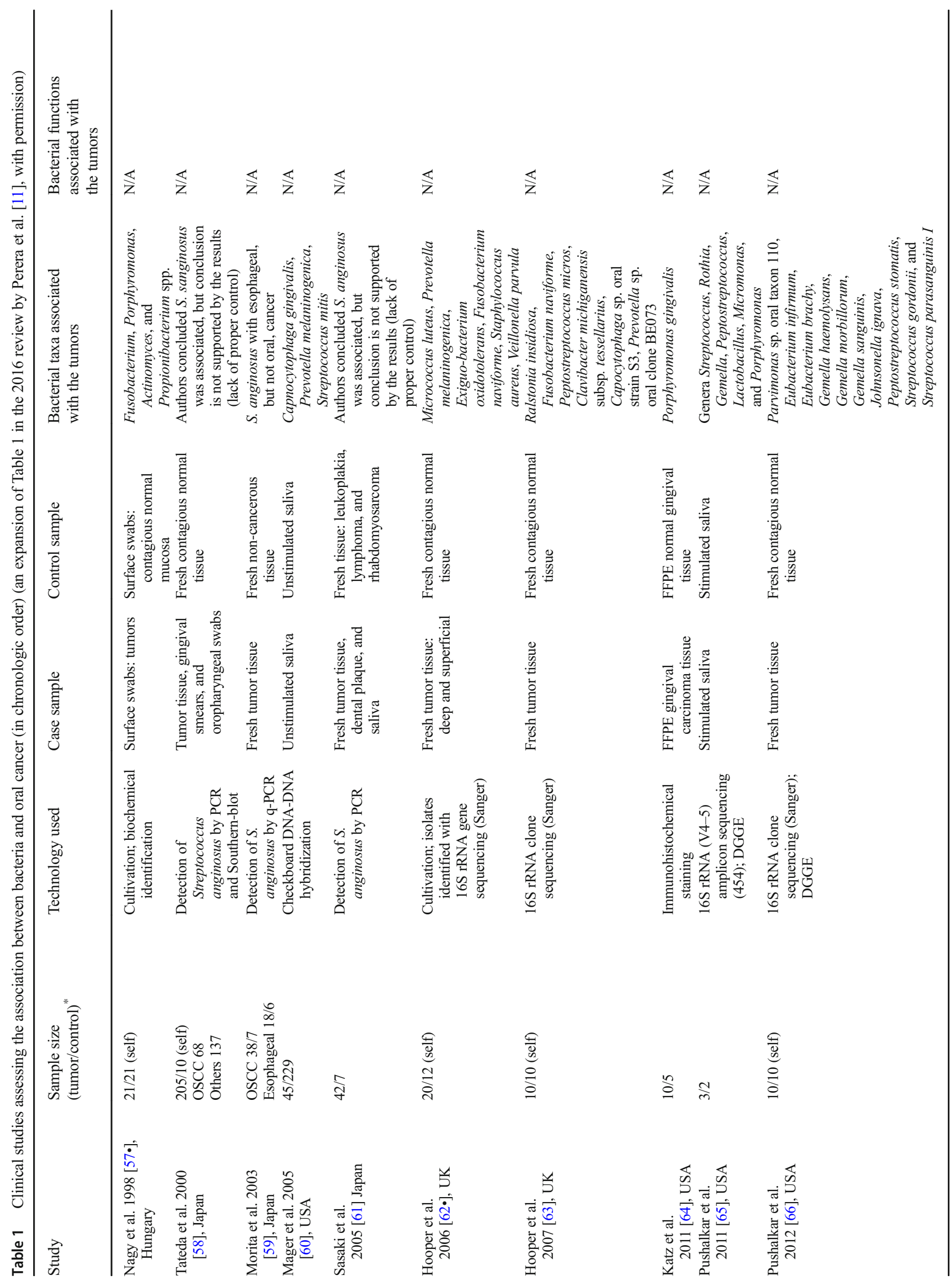




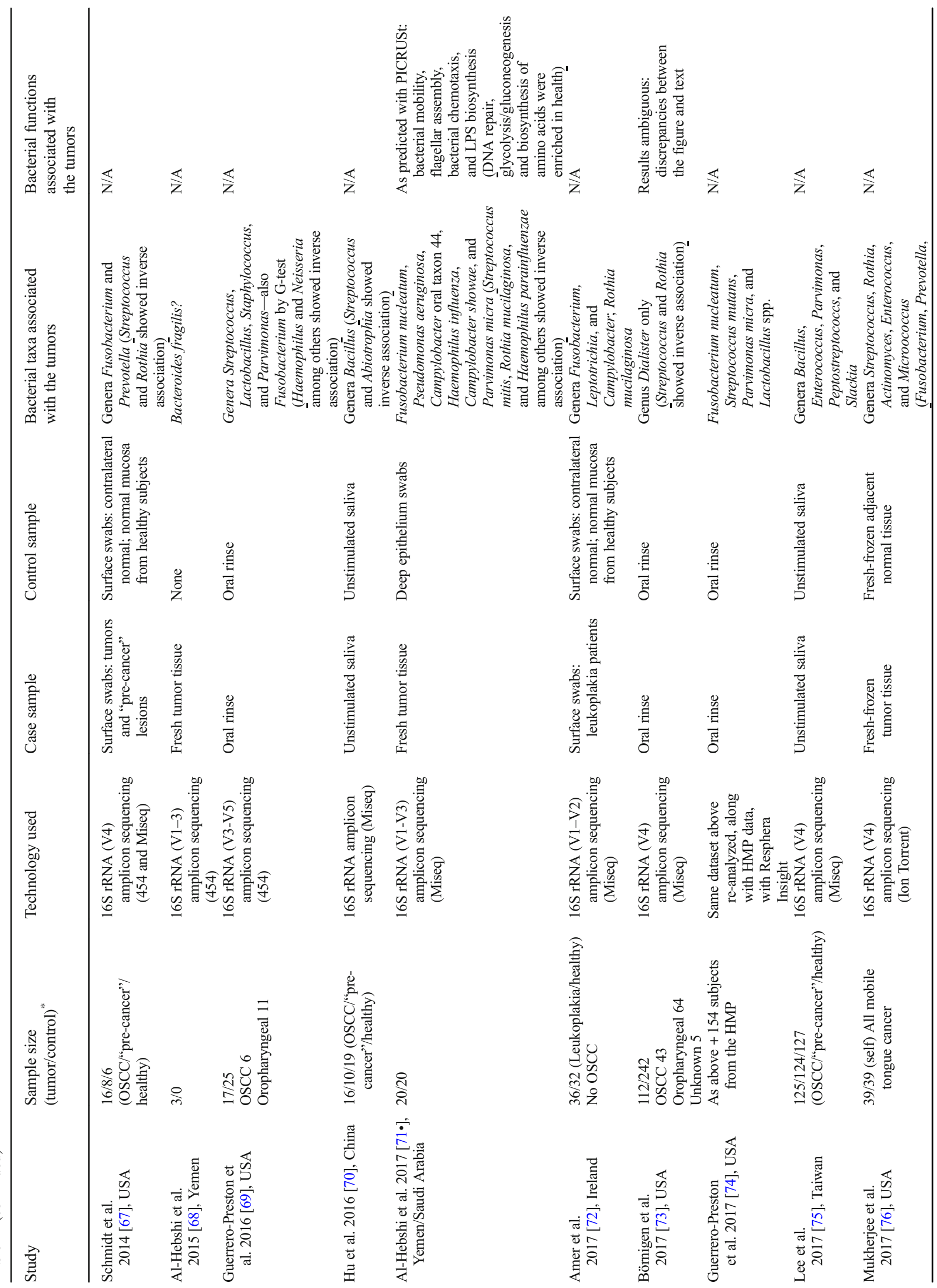




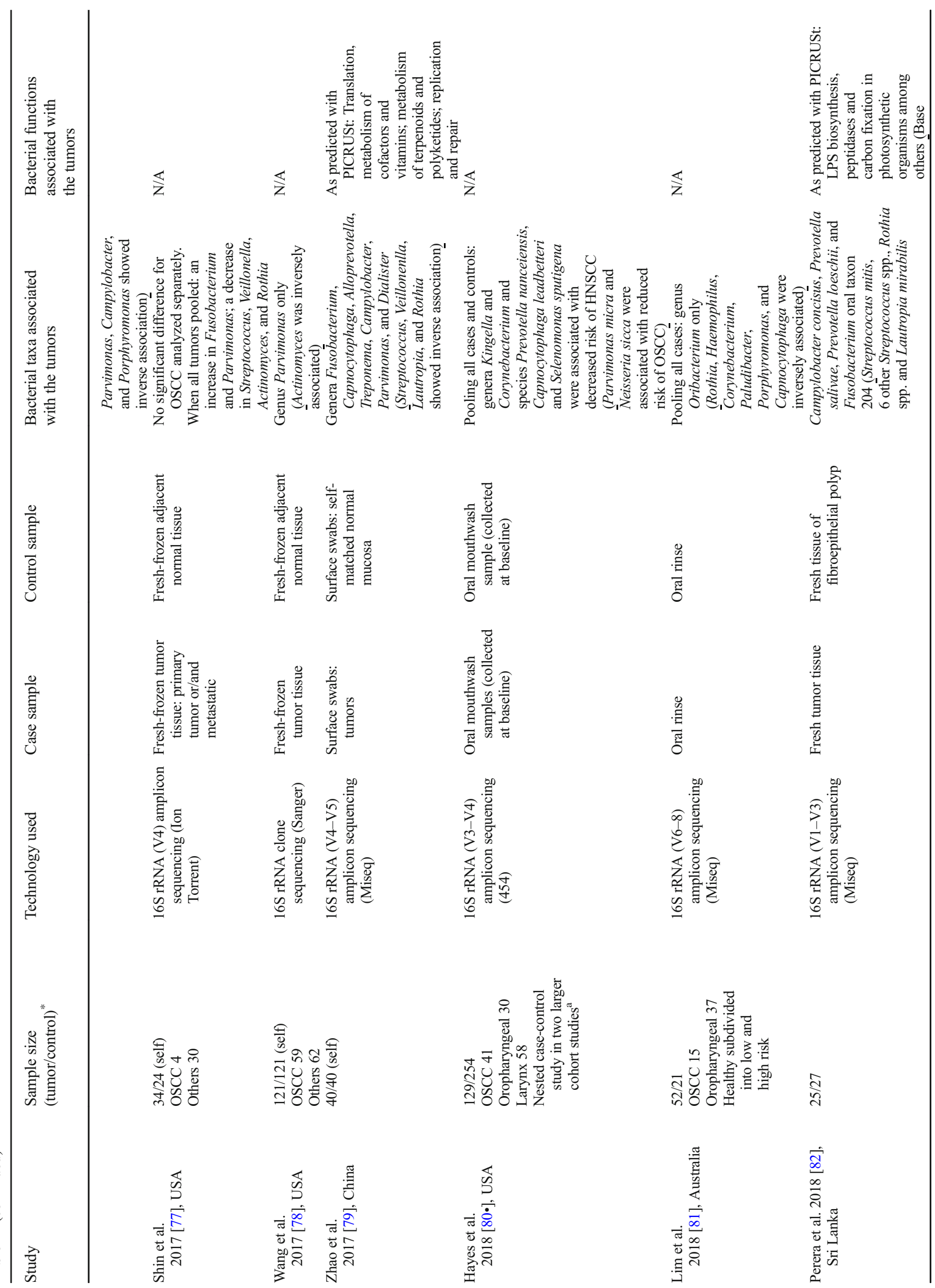




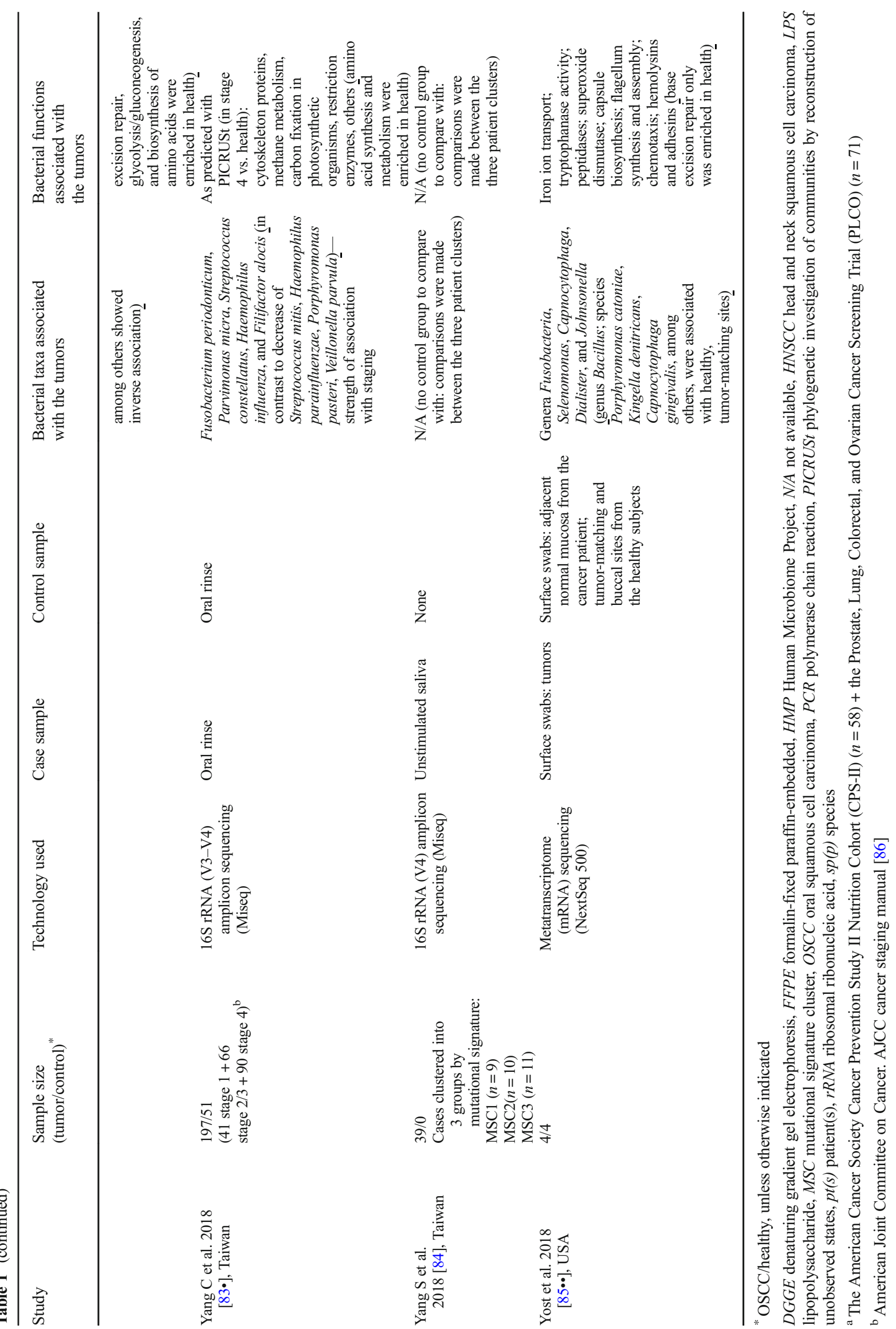


significant variations (and sometimes contradictions) in the composition of the bacteriome associated with tumors from one cohort to another, and even from one subject to another within the same cohort, especially at the species level. Overall, there is, therefore, not sufficient evidence to implicate specific bacterial species or any consortium thereof in the etiology of OSCC. Interestingly, only one of these studies identified $P$. gingivalis in association with oral cancer [64].

\section{More Consistent Results Obtained with Functional Analysis}

While the observed variation in composition of the bacteriome associated with oral cancer may, at least in part, be attributed to the methodological differences among studies described above, it may also be explained by the fact that different species frequently can serve the same functions in their communities and thus substitute for each other, a phenomenon called functional redundancy [87••]. That is, a microbial community with a certain subset of species enriched may perform the same function as another community with a different subset of overabundant species. This concept can be likened to player substitution in team sports like soccer. Indeed, functional analyses of bacteriomes associated with oral cancer produced more consistent results than those obtained with compositional profiling reflecting only the abundance/presence of specific individual members of the bacteriome. Some of the studies listed in Table 1 have used Phylogenetic Investigation of Communities by Reconstruction of Unobserved States (PICRUSt) to infer metagenomes from the $16 \mathrm{~S}$ rRNA profiles obtained (functional prediction) [71•, 79, 82, 83•]. Furthermore, in 2018 and for the first time, Yost and team used metatranscriptome sequencing to explore the transcriptional activity (gene expression) of the microbiome associated with OSCC [85••]. In these studies, the tumor-associated bacteriomes possessed similar functional signatures despite variation in their compositional profiles. For example, enrichment of primarily pro-inflammatory features, such as LPS biosynthesis, flagella assembly, bacterial chemotaxis, and production of peptidases, were enriched in the tumors, while activities like glycolysis and gluconeogenesis, amino acid synthesis and metabolism, and DNA repair were enhanced in the healthy samples. The study by Yost and colleagues identified additional virulence factors associated with OSCC, including increased expression of tryptophanase, superoxide dismutase, hemolysins, and adhesins [85••]. More details about the microbiome functional features associated with OSCC identified in this study are shown in Fig. 3 [85••].

\section{The Mycobiome Associated with Oral Cancer}

The role of members of the oral microbiome other than bacteria, namely fungi, has been studied in conjunction with
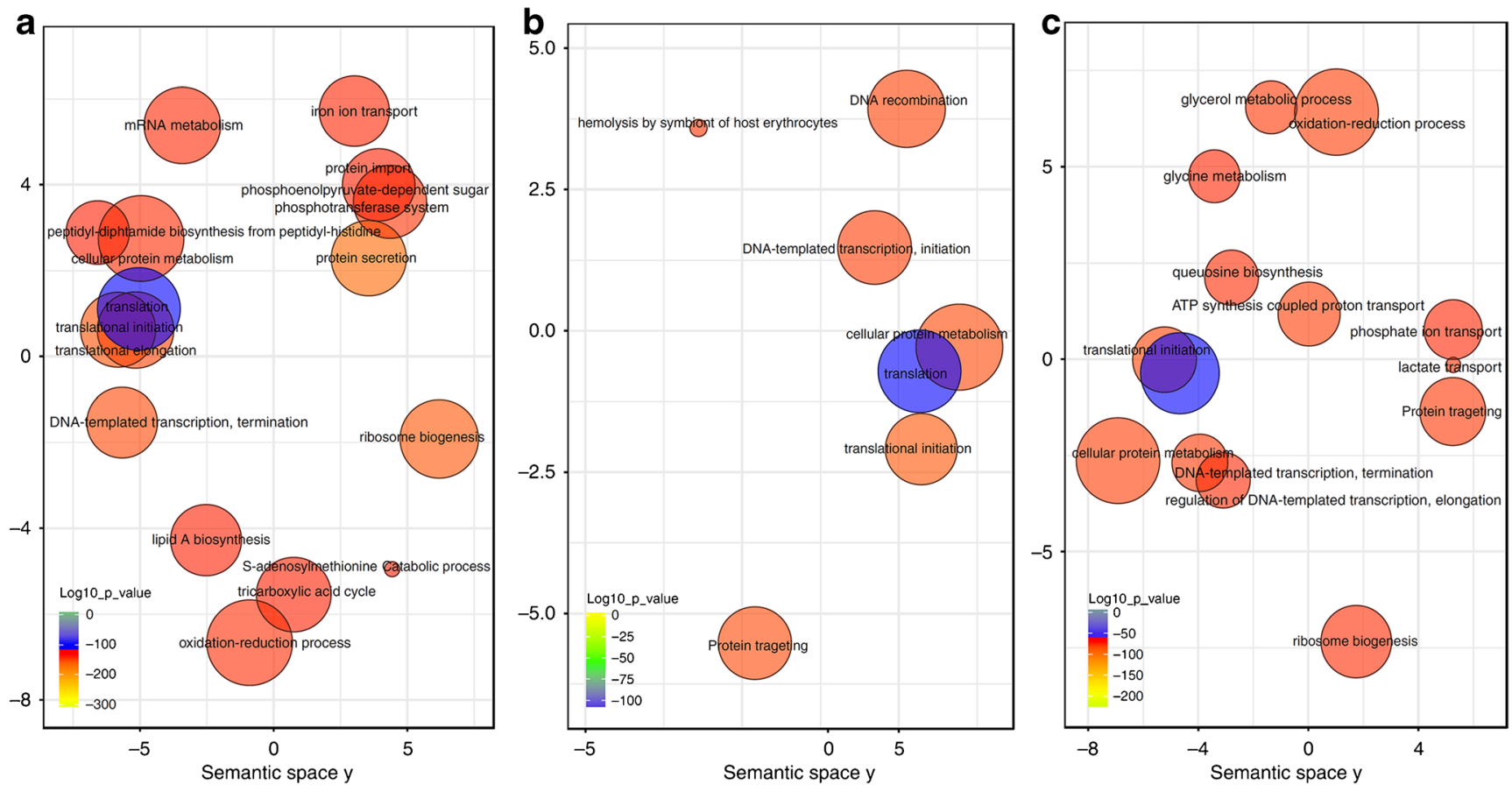

Fig. 3 Microbial pathways enriched in OSCC. The figure was reproduced with permission under Creative Commons Attribution 4.0 International License (http://creativecommons.org/licenses/by/4.0/) $[85 \bullet \cdot$. Bubbles show biological pathways that were overabundant in: a
OSCC tumor sites vs. healthy control tumor-matched, b OSCC tumor sites vs. tumor-adjacent sites, and $\mathbf{c}$ OSCC tumor-adjacent sites vs. buccal sites from healthy control subjects 


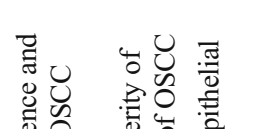

ब० 0 के

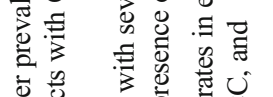

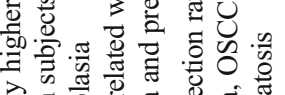

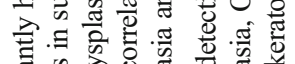

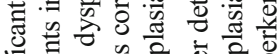

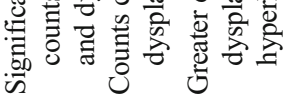

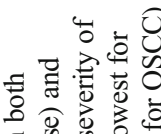

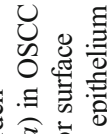

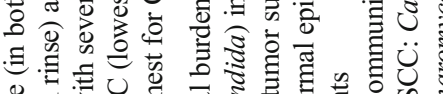

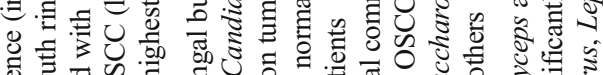

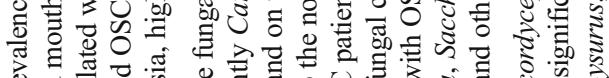

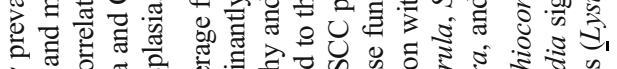
ป. 究 ช

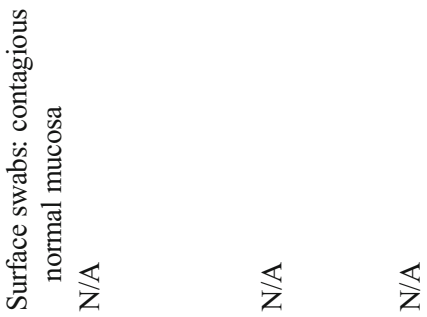

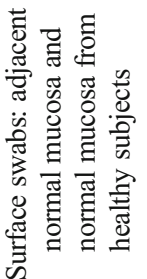<smiles>C[C@H]1C[C@H]1C[C@H]1C[C@H]1C</smiles><smiles>CC(C)C[C@@H]1[C@@H](C)C[C@H]2C[C@H]1C[C@H]2C</smiles><smiles>C1CCCCC1</smiles>

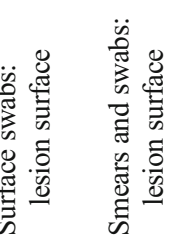

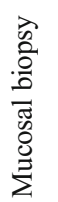

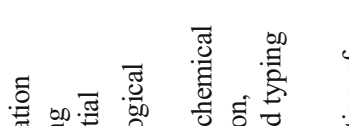

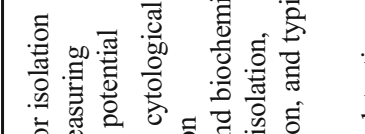

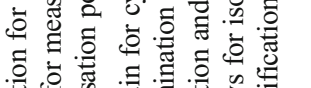

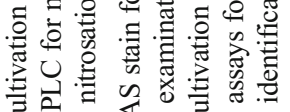

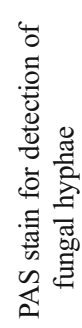
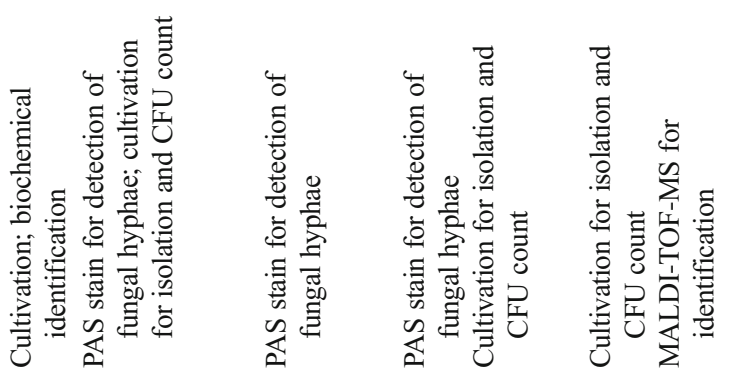

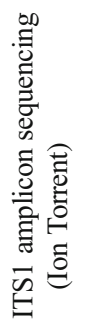
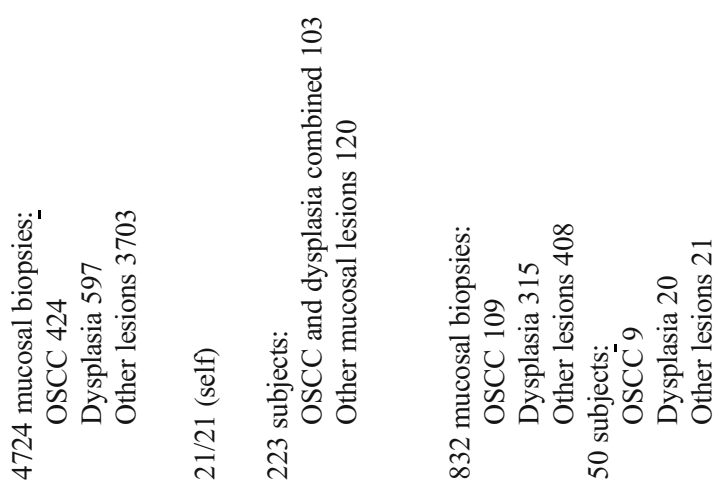

온

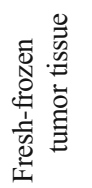

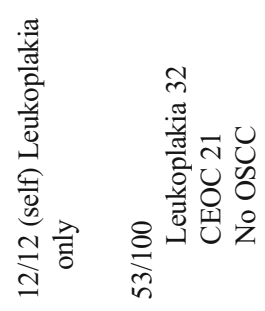

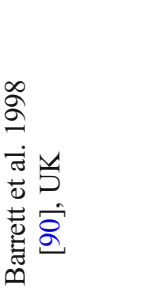

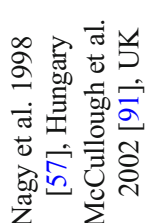

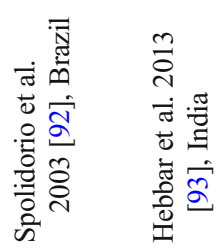

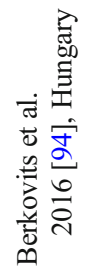


OSCC as well as potentially malignant oral lesions (Table 2). Three decades ago, Krogh's group assessed the nitrosation potential of Candida strains isolated from oral leukoplakia lesions, and found strains with high potential for nitrosation to be associated with greater levels of dysplasia [88]. A series of studies published between 1994 and 2013 used periodic Acid-Schiff (PAS) staining and cultivation techniques to detect/isolate yeasts in mucosal swabs or biopsies of oral dysplasia or OSCC [89-93]. Two studies also performed culturing and counting of colony-forming unit (CFU) in oral rinse samples [91, 93]. Most of these studies, however, did not include healthy controls, but instead used for comparison other mucosal lesions, such as hyperkeratosis, benign fibrous growths, and lichen planus. Overall, these studies found the detection frequency and counts of yeasts (predominantly Candida) to be significantly greater in dysplasia and OSCC, and such elevation correlated with the severity of dysplasia.

Because recent studies that used NGS have demonstrated that the oral fungal community (mycobiome) is far more complex than previously thought $[17,18]$, a few studies have recently re-attempted to profile the mycobiome associated with OSCC, aided by novel technology. Using cultivation techniques coupled with matrix-assisted laser desorption ionization time-of-flight mass spectrometry (MALDI-TOF MS), Berkovits and team identified a more diverse OSCCassociated fungal community, comprising Rhodotorula, Saccharomyces, and Kloeckera in addition to Candida species [94]. Consistent with earlier studies, the fungal load was also greater in OSCC compared to healthy controls. In another study, Perera and colleagues used sequencing of the Internal Transcribed Spacer (ITS) to characterize the mycobiome within OSCC tissues compared to that in fibroepithelial polyps, and found a dysbiotic mycobiome dominated by C. albicans to be associated with OSCC [96]. Interestingly, Mukherjee's team also employed ITS sequencing to profile the mycobiome in tongue cancer tissues compared to adjacent normal tissues [76]. Surprisingly, however, despite identification of significant differences, Candida was not found to be differentially abundant, neither was it the most abundant genus.

\section{"Passenger-Turning-Driver" Microbiome Model for Oral Cancer}

Synthesizing all results from the studies presented, we developed a novel "passenger-turning-driver" conceptual model of the potential role of the microbiome in oral cancer as illustrated in Fig. 4. Unlike the bacterial "driver-passenger" model for colon cancer, in which tumorigenesis is initiated by driver species that subsequently are replaced in the tumor microenvironment by passenger species that can then either suppress or promote tumor progression [97], our model assumes the oral microbiome is 


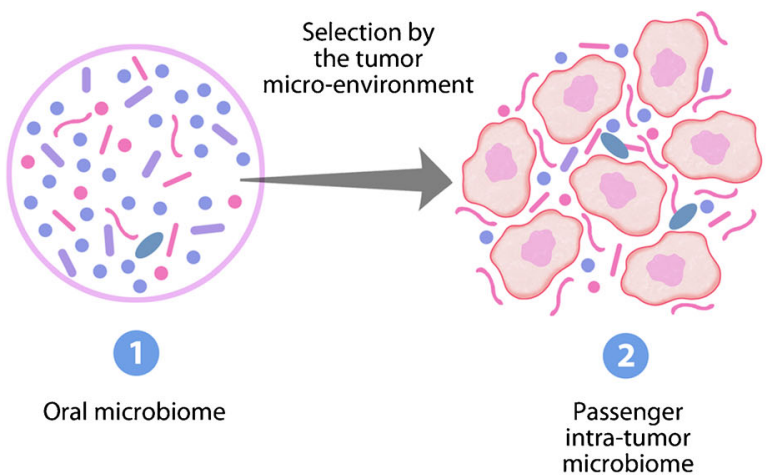

$$
\begin{aligned}
& \text { Lipopolysacchride Wh } \begin{array}{l}
\text { Flagella } \\
\text { assembly }
\end{array} \\
& \text { assis }
\end{aligned}
$$

Fig. 4 "Passenger-turning-driver" conceptual model of the sustainable role of the oral microbiome in oral cancer. 1 The commensal oral microbial community associated with healthy mucosa: a mix of bacteria (Gram-positive and Gram-negative cocci, rods, and filaments) and fungi. 2 Formation of an initially "passenger" intra-tumor microbiome by enriching a subset of microbes that can adapt to the tumor

not involved in initiation of oral cancer. Instead, we propose that the initial intra-tumor microbiome represents a passenger event that results from selection by the tumor microenvironment of a subset of species with competitive advantage, e.g., Fusobacteria, Gram-negative anaerobic rods (Prevotella, Camphylobacter, Selenomonas, etc.), anaerobic cocci (e.g., Parvimonas), and C. albicans. The particular species enriched can vary from one subject to another. As it matures, the intra-tumor microbiome expresses pro-inflammatory microbial features and virulence factors (LPS biosynthesis, flagella assembly, bacterial chemotaxis, peptidases, etc.), turning into a functionally dysbiotic, "driver" microbiome that enhances progression of oral cancer by sustaining chronic inflammation.

This conceptual model parallels the model for periodontitis pathogenesis proposed by Bartold and Van Dyke, which also is based on no particular, individual, specific, "pathogenic" bacterium being responsible for initiating the disease process $[98,99]$. Rather, certain bacteria become overabundant due to the changes in the microenvironment caused by the initial inflammation and swelling of the gingival tissues that subsequently favor the bacteria that thrive in environments with less oxygen.

\section{Conclusions}

Based on existing evidence, we conclude there are significant variations in the composition of the microbiome associated with OSCC, and there are no specific species to implicate in its etiology — of course excluding oncoviruses that are associated with a special entity of oral cancer. Rather, it is the disturbed function of an initially "passenger" microbiome within the tumor microenvironment that is likely to contribute to progression of the tumor by overexpression of virulence factors and pro-inflammatory features. These attributes are common to many taxa that can substitute for each other in different subjects. Moving forward, therefore, a functional approach, particularly metatranscriptomics, is the right way to assess the role of the microbiome in oral cancer. In addition to characterizing the transcriptional activity of the microbiome within the tumor, metatranscriptomics also provides an opportunity to explore all microbial kingdoms (viruses, phages bacteria, archaea, fungi, and protozoa) present in the tumor simultaneously, and to study the interaction between the host and microbiome if the host transcriptome is sequenced in parallel. Further research in this direction will improve our understanding of the mechanisms by which the tumor's microbial community function contributes to oral carcinogenesis and influences the behavior of the neoplasm: this may open new avenues for the diagnosis, prevention and treatment of oral cancer.

\section{Compliance with Ethical Standards}

Conflict of Interest The authors declare that they have no conflict of interest.

Human and Animal Rights and Informed Consent This article does not contain any studies with human or animal subjects performed by any of the authors. 
Open Access This article is distributed under the terms of the Creative Commons Attribution 4.0 International License (http:// creativecommons.org/licenses/by/4.0/), which permits unrestricted use, distribution, and reproduction in any medium, provided you give appropriate credit to the original author(s) and the source, provide a link to the Creative Commons license, and indicate if changes were made.

\section{References}

Papers of particular interest, published recently, have been highlighted as:

- Of importance

•- Of major importance

1. Ferlay J, Ervik M, Lam F, et al. Global Cancer Observatory: Cancer Today. Lyon, France: International Agency for Research on. Cancer. 2018; https://gco.iarc.fr/today. Accessed 19 February, 2019.

2. Gupta B, Johnson NW, Kumar N. Global epidemiology of head and neck cancers: a continuing challenge. Oncol. 2016;91(1):13-23. https://doi.org/10.1159/000446117.

3. American Cancer Society. Cancer facts \& figures 2017. Atlanta: American Cancer Society; 2017.

4. Petersen PE. Oral cancer prevention and control - the approach of the World Health Organization. Oral Oncol. 2009;45(4-5):454-60. https://doi.org/10.1016/j.oraloncology.2008.05.023.

5. Gupta B, Johnson NW. Systematic review and meta-analysis of association of smokeless tobacco and of betel quid without tobacco with incidence of oral cancer in South Asia and the Pacific. PLoS One. 2014;9(11):e113385. https://doi.org/10.1371/journal.pone. 0113385 .

6. Emmett S, Jenkins $\mathrm{G}$, Boros $\mathrm{S}$, et al. Low prevalence of human papillomavirus in oral cavity squamous cell carcinoma in Queensland, Australia. ANZ J Surg. 2017;87(9):714-9. https:// doi.org/10.1111/ans.13607.

7. Lingen MW, Xiao W, Schmitt A, et al. Low etiologic fraction for high-risk human papillomavirus in oral cavity squamous cell carcinomas. Oral Oncol. 2013;49(1):1-8. https://doi.org/10.1016/j. oraloncology.2012.07.002.

8. Shaikh MH, Khan AI, Sadat A, et al. Prevalence and types of highrisk human papillomaviruses in head and neck cancers from Bangladesh. BMC Cancer. 2017;17(1):792. https://doi.org/10. 1186/s12885-017-3789-0.

9. Sklenicka S, Gardiner S, Dierks EJ, et al. Survival analysis and risk factors for recurrence in oral squamous cell carcinoma: does surgical salvage affect outcome? J Oral Maxillofac Surg. 2010;68(6): 1270-5. https://doi.org/10.1016/j.joms.2009.11.016.

10. Wang B, Zhang S, Yue K, et al. The recurrence and survival of oral squamous cell carcinoma: a report of 275 cases. Chin J Cancer. 2013;32(11):614-8. https://doi.org/10.5732/cjc.012.10219.

11. Perera M, Al-Hebshi NN, Speicher DJ, et al. Emerging role of bacteria in oral carcinogenesis: a review with special reference to perio-pathogenic bacteria. J Oral Microbiol. 2016;8(n/a):32762. https://doi.org/10.3402/jom.v8.32762.

12. Prescott SL. History of medicine: origin of the term microbiome and why it matters. Human Microbiomed J. 2017;4(n/a):24-5. https://doi.org/10.1016/j.humic.2017.05.004.

13. Turnbaugh PJ, Ley RE, Hamady M, et al. The human microbiome project. Nature. 2007;449(7164):804-10. https://doi.org/10.1038/ nature 06244.
14. Belizario JE, Napolitano M. Human microbiomes and their roles in dysbiosis, common diseases, and novel therapeutic approaches. Front Microbiol. 2015;6(n/a):1050. https://doi.org/10.3389/fmicb. 2015.01050

15. Human Microbiome Project Consortium. Structure, function and diversity of the healthy human microbiome. Nature. 2012;486(7402):207-14. https://doi.org/10.1038/nature11234.

16. Hooks KB, O'Malley MA. Dysbiosis and its discontents. MBio. 2017;8(5):e01492-17. https://doi.org/10.1128/mBio.01492-17.

17. Dupuy AK, David MS, Li L, et al. Redefining the human oral mycobiome with improved practices in amplicon-based taxonomy: discovery of Malassezia as a prominent commensal. PLoS One. 2014;9(3):e90899. https://doi.org/10.1371/journal.pone.0090899.

18. Ghannoum MA, Jurevic RJ, Mukherjee PK, et al. Characterization of the oral fungal microbiome (mycobiome) in healthy individuals. PLoS Pathog. 2010;6(1):e1000713. https://doi.org/10.1371/ journal.ppat.1000713.

19. Perez-Brocal V, Moya A. The analysis of the oral DNA virome reveals which viruses are widespread and rare among healthy young adults in Valencia (Spain). PLoS One. 2018;13(2): e0191867. https://doi.org/10.1371/journal.pone.0191867.

20. Van Dyne EA, Henley SJ, Saraiya M, et al. Trends in human papillomavirus-associated cancers-United States, 1999-2015. MMWR Morb Mortal Wkly Rep. 2018;67(33):918-24. https:// doi.org/10.15585/mmwr.mm6733a2.

21. Johnson NW, Gupta B, Speicher DJ, et al. Chapter 2. Etiology and risk factors. In: Shah JP, Johnson NW, editors. Oral and oropharyngeal cancer. 2nd ed. Boca Raton: CRC Press, Taylor \& Francis Group; 2018. p. 19-94.

22. Shaikh MH, Idris A, Johnson NW, et al. Aurora kinases are a novel therapeutic target for HPV-positive head and neck cancers. Oral Oncol. 2018;86(n/a):105-12. https://doi.org/10.1016/j. oraloncology.2018.09.006.

23. Tsao SW, Tsang CM, Lo KW. Epstein-Barr virus infection and nasopharyngeal carcinoma. Philos Trans R Soc Lond Ser B Biol Sci. 2017;372(1732). https://doi.org/10.1098/rstb.2016.0270.

24. Al-Hebshi NN, Nasher AT, Speicher DJ, et al. Possible interaction between tobacco use and $\mathrm{EBV}$ in oral squamous cell carcinoma. Oral Oncol. 2016;59(n/a):e4-5. https://doi.org/10.1016/j. oraloncology.2016.06.005.

25. He M, Cheng F, da Silva SR, et al. Molecular biology of KSHV in relation to HIV/AIDS-associated oncogenesis. Cancer Treat Res. 2019;177(n/a):23-62. https://doi.org/10.1007/978-3-030-03502-0_2.

26. Speicher DJ, Wanzala P, D'Lima M, et al. Detecting DNA viruses in oral fluids: evaluation of collection and storage methods. Diagn Microbiol Infect Dis. 2015;82(2):120-7. https://doi.org/10.1016/j. diagmicrobio.2015.02.013.

27. Edlund A, Santiago-Rodriguez TM, Boehm TK, et al. Bacteriophage and their potential roles in the human oral cavity. J Oral Microbiol. 2015;7(n/a):27423. https://doi.org/10.3402/jom. v7.27423.

28. Kim SS, Ruiz VE, Carroll JD, et al. Helicobacter pylori in the pathogenesis of gastric cancer and gastric lymphoma. Cancer Lett. 2011;305(2):228-38. https://doi.org/10.1016/j.canlet.2010. 07.014 .

29. Markowska J, Fischer N, Markowski M, et al. The role of Chlamydia trachomatis infection in the development of cervical neoplasia and carcinoma. Med Wieku Rozwoj. 2005;9(1):83-6.

30. Nagaraja V, Eslick GD. Systematic review with meta-analysis: the relationship between chronic Salmonella typhi carrier status and gall-bladder cancer. Aliment Pharmacol Ther. 2014;39(8):745-50. https://doi.org/10.1111/apt.12655.

31. Toprak NU, Yagci A, Gulluoglu BM, et al. A possible role of Bacteroides fragilis enterotoxin in the aetiology of colorectal cancer. Clin Microbiol Infect. 2006;12(8):782-6. https://doi.org/10. $1111 /$ j.1469-0691.2006.01494.x. 
32. Ahn J, Segers S, Hayes RB. Periodontal disease, Porphyromonas gingivalis serum antibody levels and orodigestive cancer mortality. Carcinogenesis. 2012;33(5):1055-8. https://doi.org/10.1093/ carcin/bgs112.

33. Castellarin M, Warren RL, Freeman JD, et al. Fusobacterium nucleatum infection is prevalent in human colorectal carcinoma. Genome Res. 2012;22(2):299-306. https://doi.org/10.1101/gr. 126516.111

34. Kostic AD, Gevers D, Pedamallu CS, et al. Genomic analysis identifies association of Fusobacterium with colorectal carcinoma. Genome Res. 2012;22(2):292-8. https://doi.org/10.1101/gr. 126573.111.

35. Michaud DS, Izard J. Microbiota, oral microbiome, and pancreatic cancer. Cancer J. 2014;20(3):203-6. https://doi.org/10.1097/PPO. 0000000000000046

36. Yilmaz Ö, Jungas T, Verbeke P, et al. Activation of the phosphatidylinositol 3-kinase/Akt pathway contributes to survival of primary epithelial cells infected with the periodontal pathogen Porphyromonas gingivalis. Infect Immun. 2004;72(7):3743-51. https://doi.org/10.1128/IAI.72.7.3743-3751.2004.

37. Mao S, Park Y, Hasegawa Y, et al. Intrinsic apoptotic pathways of gingival epithelial cells modulated by Porphyromonas gingivalis. Cell Microbiol. 2007;9(8):1997-2007. https://doi.org/10.1111/j. 1462-5822.2007.00931.x.

38. Yao L, Jermanus C, Barbetta B, et al. Porphyromonas gingivalis infection sequesters pro-apoptotic Bad through Akt in primary gingival epithelial cells. Mol Oral Microbiol. 2010;25(2):89-101. https://doi.org/10.1111/j.2041-1014.2010.00569.x.

39. Moffatt CE, Lamont RJ. Porphyromonas gingivalis induction of microRNA-203 expression controls suppressor of cytokine signaling 3 in gingival epithelial cells. Infect Immun. 2011;79(7):2632-7. https://doi.org/10.1128/IAI.00082-11.

40. Yilmaz Ö, Yao L, Maeda K, et al. ATP scavenging by the intracellular pathogen Porphyromonas gingivalis inhibits P2X7-mediated host-cell apoptosis. Cell Microbiol. 2008;10(4):863-75. https://doi. org/10.1111/j.1462-5822.2007.01089.x

41. Kuboniwa M, Hasegawa $\mathrm{Y}$, Mao S, et al. P. gingivalis accelerates gingival epithelial cell progression through the cell cycle. Microbes Infect. 2008;10(2):122-8. https://doi.org/10.1016/j.micinf.2007.10. 011.

42. Pan $\mathrm{C}, \mathrm{Xu} \mathrm{X}, \mathrm{Tan} \mathrm{L}$, et al. The effects of Porphyromonas gingivalis on the cell cycle progression of human gingival epithelial cells. Oral Dis. 2014;20(1):100-8. https://doi.org/10.1111/odi.12081.

43. Uitto VJ, Baillie D, Wu Q, et al. Fusobacterium nucleatum increases collagenase 3 production and migration of epithelial cells. Infect Immun. 2005;73(2):1171-9. https://doi.org/10.1128/IAI.73. 2.1171-1179.2005.

44. Zhou Y, Sztukowska M, Wang Q, et al. Noncanonical activation of beta-catenin by Porphyromonas gingivalis. Infect Immun. 2015;83(8):3195-203. https://doi.org/10.1128/IAI.00302-15.

45. Rubinstein MR, Wang X, Liu W, et al. Fusobacterium nucleatum promotes colorectal carcinogenesis by modulating E-cadherin $/ \beta$ catenin signaling via its FadA adhesin. Cell Host Microbe. 2013;14(2):195-206. https://doi.org/10.1016/j.chom.2013.07.012.

46. Inaba $\mathrm{H}$, Sugita $\mathrm{H}$, Kuboniwa $\mathrm{M}$, et al. Porphyromonas gingivalis promotes invasion of oral squamous cell carcinoma through induction of proMMP9 and its activation. Cell Microbiol. 2014;16(1): 131-45. https://doi.org/10.1111/cmi.12211.

47. Inaba $\mathrm{H}$, Amano A, Lamont RJ, et al. Involvement of proteaseactivated receptor 4 in over-expression of matrix metalloproteinase 9 induced by Porphyromonas gingivalis. Med Microbiol Immunol. 2015;204(5):605-12. https://doi.org/10.1007/s00430-015-0389-y.

48. Ha NH, Woo BH, Kim d J, et al. Prolonged and repetitive exposure to Porphyromonas gingivalis increases aggressiveness of oral cancer cells by promoting acquisition of cancer stem cell properties.
Tumour Biol. 2015;36(12):9947-60. https://doi.org/10.1007/ s13277-015-3764-9.

49. Andrian E, Grenier D, Rouabhia M. In vitro models of tissue penetration and destruction by Porphyromonas gingivalis. Infect Immun. 2004;72(8):4689-98. https://doi.org/10.1128/IAI.72.8. 4689-4698.2004.

50. Groeger S, Domann E, Gonzales JR, et al. B7-H1 and B7-DC receptors of oral squamous carcinoma cells are upregulated by Porphyromonas gingivalis. Immunobiology. 2011;216(12):130210. https://doi.org/10.1016/j.imbio.2011.05.005.

51. Kostic AD, Chun E, Robertson L, et al. Fusobacterium nucleatum potentiates intestinal tumorigenesis and modulates the tumorimmune microenvironment. Cell Host Microbe. 2013;14(2):20715. https://doi.org/10.1016/j.chom.2013.07.007.

52. McCoy AN, Araujo-Perez F, Azcarate-Peril A, et al. Fusobacterium is associated with colorectal adenomas. PLoS ONE. 2013;8(1): e53653. https://doi.org/10.1371/journal.pone.0053653.

53. Kurkivuori J, Salaspuro V, Kaihovaara P, et al. Acetaldehyde production from ethanol by oral streptococci. Oral Oncol. 2007;43(2): 181-6. https://doi.org/10.1016/j.oraloncology.2006.02.005.

54. Muto M, Hitomi Y, Ohtsu A, et al. Acetaldehyde production by non-pathogenic Neisseria in human oral microflora: implications for carcinogenesis in upper aerodigestive tract. Int $\mathrm{J}$ Cancer. 2000;88(3):342-50. https://doi.org/10.1002/1097-0215(20001101) 88:3<342::AID-IJC4>3.0.CO;2-I.

55. Gainza-Cirauqui ML, Nieminen MT, Novak Frazer L, et al. Production of carcinogenic acetaldehyde by Candida albicans from patients with potentially malignant oral mucosal disorders. J Oral Pathol Med. 2013;42(3):243-9. https://doi.org/10.1111/j. 1600-0714.2012.01203.x.

56. Nieminen MT, Uittamo J, Salaspuro M, et al. Acetaldehyde production from ethanol and glucose by non-Candida albicans yeasts in vitro. Oral Oncol. 2009;45(12):e245-8. https://doi.org/10.1016/j. oraloncology.2009.08.002.

57. Nagy KN, Sonkodi I, Szoke I, et al. The microflora associated with human oral carcinomas. Oral Oncol. 1998;34(4):304-8. https://doi. org/10.1016/S1368-8375(98)80012-2 Based on the available culturing techniques, this study was the first to identify compositional differences in the microbial community colonizing the surface of OSCC vs adjacent clinically healthy tissue.

58. Tateda M, Shiga K, Saijo S, et al. Streptococcus anginosus in head and neck squamous cell carcinoma: implication in carcinogenesis. Int J Mol Med. 2000;6(6):699-703. https://doi.org/10.3892/ijmm.6. 6.699 .

59. Morita E, Narikiyo M, Yano A, et al. Different frequencies of Streptococcus anginosus infection in oral cancer and esophageal cancer. Cancer Sci. 2003;94(6):492-6. https://doi.org/10.1111/j. 1349-7006.2003.tb01471.x.

60. Mager DL, Haffajee AD, Devlin PM, et al. The salivary microbiota as a diagnostic indicator of oral cancer: a descriptive, nonrandomized study of cancer-free and oral squamous cell carcinoma subjects. J Transl Med. 2005;3:27. https://doi.org/10.1186/14795876-3-27.

61. Sasaki M, Yamaura C, Ohara-Nemoto Y, et al. Streptococcus anginosus infection in oral cancer and its infection route. Oral Dis. 2005;11(3):151-6. https://doi.org/10.1111/j.1601-0825.2005. 01051.x.

62. Hooper SJ, Crean SJ, Lewis MA, et al. Viable bacteria present within oral squamous cell carcinoma tissue. J Clin Microbiol. 2006;44(5):1719-25. https://doi.org/10.1128/JCM.44.5.17191725.2006 This study demonstrated for the first time the presence of a viable microbial community within the tissue of OSCC.

63. Hooper SJ, Crean SJ, Fardy MJ, et al. A molecular analysis of the bacteria present within oral squamous cell carcinoma. J Med 
Microbiol. 2007;56(Pt 12):1651-9. https://doi.org/10.1099/jmm.0. 46918-0.

64. Katz J, Onate MD, Pauley KM, et al. Presence of Porphyromonas gingivalis in gingival squamous cell carcinoma. Int J Oral Sci. 2011;3(4):209-15. https://doi.org/10.4248/IJOS11075.

65. Pushalkar S, Mane SP, Ji X, et al. Microbial diversity in saliva of oral squamous cell carcinoma. FEMS Immunol Med Microbiol. 2011;61(3):269-77. https://doi.org/10.1111/j.1574-695X.2010. 00773.x.

66. Pushalkar S, Ji X, Li Y, et al. Comparison of oral microbiota in tumor and non-tumor tissues of patients with oral squamous cell carcinoma. BMC Microbiol. 2012;12(n/a):144. https://doi.org/10. 1186/1471-2180-12-144.

67. Schmidt BL, Kuczynski J, Bhattacharya A, et al. Changes in abundance of oral microbiota associated with oral cancer. PLoS One. 2014;9(6):e98741. https://doi.org/10.1371/journal.pone.0098741.

68. Al-Hebshi NN, Nasher AT, Idris AM, et al. Robust species taxonomy assignment algorithm for $16 \mathrm{~S}$ rRNA NGS reads: application to oral carcinoma samples. J Oral Microbiol. 2015;7(n/a):28934. https://doi.org/10.3402/jom.v7.28934.

69. Guerrero-Preston R, Godoy-Vitorino F, Jedlicka A, et al. 16S rRNA amplicon sequencing identifies microbiota associated with oral cancer, human papilloma virus infection and surgical treatment. Oncotarget. 2016;7(32):51320-34. https://doi.org/10.18632/ oncotarget.9710

70. Hu X, Zhang Q, Hua H, et al. Changes in the salivary microbiota of oral leukoplakia and oral cancer. Oral Oncol. 2016;56(n/a):e6-8. https://doi.org/10.1016/j.oraloncology.2016.03.007.

71. Al-Hebshi NN, Nasher AT, Maryoud MY, et al. Inflammatory bacteriome featuring Fusobacterium nucleatum and Pseudomonas aeruginosa identified in association with oral squamous cell carcinoma. Sci Rep. 2017;7(1):1834. https://doi.org/10. 1038/s41598-017-02079-3 This is the first attempt to perform functional analysis of the microbiome associated with OSCC and to describe it as being inflammatory.

72. Amer A, Galvin S, Healy CM, et al. The microbiome of potentially malignant oral leukoplakia exhibits enrichment for Fusobacterium, Leptotrichia, Campylobacter, and Rothia species. Front Microbiol. 2017;8(2391):2391. https://doi.org/10.3389/fmicb.2017.02391.

73. Börnigen D, Ren B, Pickard R, et al. Alterations in oral bacterial communities are associated with risk factors for oral and oropharyngeal cancer. Sci Rep. 2017;7(1):17686. https://doi.org/10.1038/ s41598-017-17795-z.

74. Guerrero-Preston R, White JR, Godoy-Vitorino F, et al. Highresolution microbiome profiling uncovers Fusobacterium nucleatum, Lactobacillus gasseri/johnsonii, and Lactobacillus vaginalis associated to oral and oropharyngeal cancer in saliva from HPV positive and HPV negative patients treated with surgery and chemo-radiation. Oncotarget. 2017;8(67):110931-48. https://doi. org/10.18632/oncotarget.20677.

75. Lee WH, Chen HM, Yang SF, et al. Bacterial alterations in salivary microbiota and their association in oral cancer. Sci Rep. 2017;7(1): 16540. https://doi.org/10.1038/s41598-017-16418-x.

76. Mukherjee PK, Wang H, Retuerto $M$, et al. Bacteriome and mycobiome associations in oral tongue cancer. Oncotarget. 2017;8(57):97273-89. https://doi.org/10.18632/oncotarget.21921.

77. Shin JM, Luo T, Kamarajan P, et al. Microbial communities associated with primary and metastatic head and neck squamous cell carcinoma - a high Fusobacterial and low Streptococcal signature. Sci Rep. 2017;7(1):9934. https://doi.org/10.1038/s41598-01709786-x.

78. Wang H, Funchain P, Bebek G, et al. Microbiomic differences in tumor and paired-normal tissue in head and neck squamous cell carcinomas. Genome Med. 2017;9(1):14. https://doi.org/10.1186/ s13073-017-0405-5.
79. Zhao $\mathrm{H}$, Chu $\mathrm{M}$, Huang Z, et al. Variations in oral microbiota associated with oral cancer. Sci Rep. 2017;7(1):11773. https://doi. org/10.1038/s41598-017-11779-9.

80. Hayes RB, Ahn J, Fan X, et al. Association of oral microbiome with risk for incident head and neck squamous cell cancer. JAMA Oncol. 2018;4(3):358-65. https://doi.org/10.1001/jamaoncol.2017.4777 This longitudinal study assessed whether baseline oral microbiome signature can influence the risk of developing OSCC.

81. Lim Y, Fukuma N, Totsika M, et al. The performance of an oral microbiome biomarker panel in predicting oral cavity and oropharyngeal cancers. Front Cell Infect Microbiol. 2018;8(n/a):267. https://doi.org/10.3389/fcimb.2018.00267.

82. Perera M, Al-Hebshi NN, Perera I, et al. inflammatory bacteriome and oral squamous cell carcinoma. J Dent Res. 2018;97(6):725-32. https://doi.org/10.1177/0022034518767118.

83. Yang CY, Yeh YM, Yu HY, et al. Oral microbiota community dynamics associated with oral squamous cell carcinoma staging. Front Microbiol. 2018;9(862):862. https://doi.org/10.3389/fmicb.2018. 00862 This study showed the relative abundance of a number of bacterial species to significantly correlate with staging of OSCC.

84. Yang SF, Huang HD, Fan WL, et al. Compositional and functional variations of oral microbiota associated with the mutational changes in oral cancer. Oral Oncol. 2018;77:1-8. https://doi.org/10.1016/j. oraloncology.2017.12.005.

85.• Yost S, Stashenko P, Choi Y, et al. Increased virulence of the oral microbiome in oral squamous cell carcinoma revealed by metatranscriptome analyses. Int J Oral Sci. 2018;10(4):32. https:// doi.org/10.1038/s41368-018-0037-7 This is the only study so far that used metatranscriptome sequencing to assess the function/ gene expression of the microbiome associated with OSCC. Transcripts of virulence factors and pro-inflammatory features were found to be enriched in the tumor samples.

86. American Joint Committee on Cancer. AJCC cancer staging manual. 7th Ed. 2010. https://cancerstaging.org/references-tools/ deskreferences/Documents/AJCC\%207th\%20Ed\%20Cancer\% 20Staging\%20Manual.pdf. Accessed 19 Feb, 2019.

87.• Tian L, Wu A-K, Friedman J, et al. Deciphering functional redundancy in the human microbiome. bioRxiv. 2017;(n/a):176313. https://doi.org/10.1101/176313 This is a key article that provides insight and mathematical modeling of the concept of functional redundancy. It highlights the importance of a function-based approach to studying the human-associated microbiomes and not relying on only microbial profiles based on their abundance.

88. Krogh P, Hald B, Holmstrup P. Possible mycological etiology of oral mucosal cancer: catalytic potential of infecting Candida albicans and other yeasts in production of $\mathrm{N}$ nitrosobenzylmethylamine. Carcinogenesis. 1987;8(10):1543-8. https://doi.org/10.1093/carcin/8.10.1543.

89. Rindum JL, Stenderup A, Holmstrup P. Identification of Candida albicans types related to healthy and pathological oral mucosa. $\mathrm{J}$ Oral Pathol Med. 1994;23(9):406-12. https://doi.org/10.1111/j. 1600-0714.1994.tb00086.x.

90. Barrett AW, Kingsmill VJ, Speight PM. The frequency of fungal infection in biopsies of oral mucosal lesions. Oral Dis. 1998;4(1): 26-31. https://doi.org/10.1111/j.1601-0825.1998.tb00251.x.

91. McCullough M, Jaber M, Barrett AW, et al. Oral yeast carriage correlates with presence of oral epithelial dysplasia. Oral Oncol. 2002;38(4):391-3. https://doi.org/10.1016/S1368-8375(01)000793.

92. Spolidorio LC, Martins VR, Nogueira RD, et al. The frequency of Candida sp. in biopsies of oral mucosal lesions. [Portugese]. Pesqui Odontol Bras. 2003;17(1):89-93. https://doi.org/10.1590/S151774912003000100017 . 
93. Hebbar PB, Pai A, Sujatha D. Mycological and histological associations of Candida in oral mucosal lesions. J Oral Sci. 2013;55(2): 157-60. https://doi.org/10.2334/josnusd.55.157.

94. Berkovits C, Toth A, Szenzenstein J, et al. Analysis of oral yeast microflora in patients with oral squamous cell carcinoma. Springerplus. 2016;5(1):1257. https://doi.org/10.1186/s40064016-2926-6.

95. Perera M, Al-Hebshi NN, Perera I, et al. A dysbiotic mycobiome dominated by Candida albicans is identified within oral squamouscell carcinomas. J Oral Microbiol. 2017;9(1):1385369. https://doi. org/10.1080/20002297.2017.1385369 This study characterized the mycobiome present within OSCC tissues at the species-level using 16S rRNA sequencing.

96. Perera I, Ekanayake L. Prevalence of oral impacts in a Sinhalaspeaking older population in urban Sri Lanka. Community Dent Health. 2003;20(4):236-40.
97. Tjalsma H, Boleij A, Marchesi JR, et al. A bacterial driverpassenger model for colorectal cancer: beyond the usual suspects. Nat Rev Microbiol. 2012;10(8):575-82. https://doi.org/10.1038/ nrmicro2819.

98. Bartold PM, Van Dyke TE. Periodontitis: a host-mediated disruption of microbial homeostasis. Unlearning learned concepts. Periodontol. 2013;62(1):203-17. https://doi.org/10.1111/j.16000757.2012.00450.x.

99. Bartold PM, Van Dyke TE. An appraisal of the role of specific bacteria in the initial pathogenesis of periodontitis. J Clin Periodontol. In press. https://doi.org/10.1111/jcpe.13046.

Publisher's Note Springer Nature remains neutral with regard to jurisdictional claims in published maps and institutional affiliations. 